UPPSALA UNIVERSITET

Working Paper 2007:28

Department of Economics

\title{
Is There an Incumbency Advantage or a Cost of Ruling in Proportional Election Systems?
}

Che-Yuan Liang 
Department of Economics

Working paper 2007:28

Uppsala University

P.O. Box 513

December 2007

SE-751 20 Uppsala

Sweden

Fax: +46184711478

Is There an Incumbency Advantage or a Cost of Ruling in Proportional Election Systems?

Che-YuAn Liang

Papers in the Working Paper Series are published on internet in PDF formats.

Download from http://www.nek.uu.se

or from S-WoPEC http://swopec.hhs.se/uunewp/ 


\title{
Is There an Incumbency Advantage or a Cost of Ruling in Proportional Election Systems?*
}

\author{
December 2007 \\ Che-Yuan Liang ${ }^{\#}$
}

\begin{abstract}
This paper investigates the effect of political representation on the electoral outcome at the party level in a proportional multiparty election system using data from Swedish local government elections. There are two notions of representation in a council; the first is to hold seats, and the second is to belong to the ruling coalition. I refer to the effect of the former as the incumbency effect and the effect of the latter as the effect of ruling. To identify causal effects, I use the discontinuous variations in the number of seats and ruling (as a coalition receives a majority of the seats) to isolate exogenous variation in incumbency and ruling respectively. I find an advantage of 0.11 percent of the votes for each percent of incumbency. 11 percent of the votes in an election are therefore determined by incumbency, a figure close to the advantage found in majoritarian systems. However, the advantage differs significantly between parties. Further, I find no effects of ruling, contrary to the commonly found cost of ruling in proportional systems.
\end{abstract}

Keywords: incumbency advantage, cost of ruling, proportional elections, multiparty systems, local governments, regression-discontinuity

JEL classification: D72, D73

\footnotetext{
* I thank Sören Blomquist, Olle Folke, and Henrik Jordahl for valuable comments and suggestions and the Jan Wallander and Tom Hedelius Foundation for financial support.

\# Department of Economics, Uppsala University, P.O. Box 513, SE-751 20 Uppsala, Sweden; che-yuan.liang@nek.uu.se
} 


\section{INTRODUCTION}

It is a well-known fact that incumbent politicians enjoy an electoral advantage in singlemember-district winner-takes-it-all majoritarian election systems with two dominating parties. The incumbency advantage literature that establishes this result usually examines the U.S. House of Representatives. For multi-member-district proportional election systems with a larger number of parties, the vote function literature finds the reverse relationship: a cost of ruling. Although striking, the different results are not directly comparable as the incumbency advantage usually pertains to incumbent legislators, whereas the cost of ruling usually pertains to ruling parties. In addition, the incumbency advantage literature uses sophisticated identification strategies, whereas the vote function literature produces the cost of ruling result as a peripheral byproduct as the main focus usually are on other economical determinants of the electoral outcome.

This paper investigates the effect of political representation on the electoral outcome at the party level in a proportional multiparty system using data from seven consecutive Swedish local government elections. First, I examine the representational effect of holding seats in the local government council, henceforth referred to as the incumbency effect. I use the fact that the number of seats varies discontinuously with the election result to isolate exogenous variation in incumbency. ${ }^{1}$ I find an economically and statistically significant advantage of 0.11 percent of the votes for each percent of incumbency. 11 percent of the votes in an election are therefore determined by incumbency. The advantage differs however significantly between parties. Second, I examine the representational effect of belonging to the ruling coalition, henceforth referred to as the effect of ruling. I use a regression-discontinuity design where the discontinuous variation in ruling as coalitions receive more than 50 percent of the seats provides exogenous variation as in Lee (2007). I find no effects of ruling.

The empirical strategies commonly used to estimate the incumbent legislator advantage can according to Lee (2007) be divided into three categories. The sophomore surge strategy (e.g. Erikson 1971) uses the difference in election results between the first and second term for first-term winning challengers. The retirement slump strategy (e.g. Collie 1981) uses the difference between last-period winning incumbents and their freshmen successors instead. Finally, the Gelman-King strategy (e.g. Gelman and King 1990) uses the difference between

\footnotetext{
${ }^{1}$ This is the same variation used for identification by Olle Folke in an ongoing project on party effects on a number of economical outcome variables. The idea that this variation also could be used to examine the incumbency effect on the electoral outcome was mentioned to me by Henrik Jordahl.
} 
all incumbents and freshmen successors. The incumbent party effect includes the legislator effect, but might have other components as well. Lee (2007) analyzes this party effect in the U.S. House of Representatives using a regression-discontinuity approach that essentially compares close winners and losers. Estimates of the incumbency advantage are usually of the order of ten percent of all votes in the coming election.

The most commonly suggested explanation is that incumbents have more resources at their disposal than challengers have. Holding office entails larger opportunities to promote popularity through medial exposure, which improve fund-raising capabilities for electoral campaigns. Funds can in turn be spent on building image which affects the electoral outcome. Another resource is the extra experience that incumbents get by being in office an extra term compared to their competitors. An indirect effect of resources is that some challengers are scared off to candidate in face of this asymmetry. Cox and Katz (1996) find that all these components contribute significantly to the advantage. There are also other differences between incumbents and challengers; Bernhardt and Ingerman (1985) show that voters perceive incumbents to be less risky alternatives due to reputational mechanisms, and Andersson and Glomm (1992) point out that incumbents are first-movers in selecting electoral platforms, a fact that often is a disadvantage rather than an advantage.

The cost of ruling result is presented in several papers in the vote function literature, which examines determinants of electoral outcome. A few papers (e.g. Paldam 1986) look for basic statistical regularities in the distribution of election results. However, most papers use simple kitchen-sink regression approaches (see Nannestad and Paldam 1994 for a survey on this literature). Estimates of the cost of ruling are usually of the order two percent of all votes. However, this effect cannot be considered to be causal, which the authors neither claim.

Paldam (1986) suggests a back-swinging hypothesis to explain the cost of ruling. A party's popularity is assumed to have a stationary and a temporary component that on average is zero. When parties are temporarily successful, they are more likely to belong to ruling coalitions. However, they are also more likely to perform worse in the next election, as they tend to back-swing to their natural stationary level. The hypothesis reduces the cost of ruling to a spurious relationship that should disappear once the temporary component is controlled for. Mueller (1971) advances an asymmetric voter-reaction hypothesis, according to which the voters reward ruling coalitions less for good events than they punish them for bad events. The most elaborated hypothesis is however Paldam and Skott's (1995) median-gap model. They use a two-party median-voter framework and analyze a divergent equilibrium where the parties locate on each side of the median voter. In such a situation the median voter 
alternatingly votes for the two parties to moderate the average policy toward his position. Since his vote is decisive, power shifts forth and back.

The arguments in both literatures are to some degree applicable in both majoritarian and proportional election systems. It is e.g. plausible that resources also depend on representation in proportional systems, and voters may respond asymmetrically to good and bad events even in majoritarian systems. It is therefore theoretically unclear whether representation has a positive or negative impact on the election result.

When it comes to evaluating and comparing the empirical evidence in the two different systems, it is important to distinguish between the two different representational effects of incumbency and ruling respectively. In majoritarian election systems these two effects coincide, but not in proportional systems. ${ }^{2}$ The incumbency advantage literature supports the presence of a large incumbency advantage (and hence an advantage of ruling) in majoritarian systems. The vote function literature on the other hand shows a small negative association between ruling and election results. However, there are serious doubts concerning whether this cost of ruling result is a causal effect of ruling.

This paper makes two major contributions to the understanding of the representational effects in proportional election systems. First, it examines the incumbency effect, an effect that, as far as I know, has not been examined before. Second, it examines the effect of ruling using a particular credible design for causal inference - the regression discontinuity design.

The paper proceeds as follows. Next section presents the institutional background and the data used. Section three outlines the empirical strategy and section four presents the results. The last section concludes.

\section{SWEDISH ELECTION DATA}

Sweden has three levels of governments: the central government, the counties and the municipalities. There are 21 counties (24 before 1998) and 290 municipalities in 2006. The local governments are major actors in the Swedish economy. The counties are responsible for public health care and the municipalities for day care, education, and care of the elderly. Their share of the national GDP spending is around 20 percent, one third spent by the counties and

\footnotetext{
${ }^{2}$ Note that according to my definitions of the incumbency effect and the effect of ruling, there could be an incumbency advantage and a cost of ruling in proportional systems. The "or" in the title is therefore not a mutually exclusive "or".
} 
two thirds by the municipalities. They employ around 25 percent of the total Swedish workforce. The municipalities are the local governments of interest in this study.

Each municipality has a council and the law prescribes a minimum size depending on the number of eligible voters. Elections are held simultaneously as the election to the parliament every third year before 1994 and every fourth year after that. Election date is the third Sunday in September. I use a complete data set, obtained from Statistics Sweden, for the period 1982 -2006 spanning eight elections. Pre-eighties data are not easily accessible and somewhat problematic to merge with the current sample as there were several extensive municipal amalgamation reforms in the fifties, sixties and seventies. During the sample period, 10 municipalities were split into 21. I include these municipalities as this increases precision a bit. Except for this, the results in this paper are insensitive to their exclusion.

The election system is a multi-member-district proportional system where the seats are assigned to parties according to the modified Saint-Lagues highest averages method. ${ }^{3}$ In the parliamentary elections, there is an explicit small party barrier of four percent that excludes small parties from receiving seats, but not in the municipal elections. Before 1998 the parties had full power of the ordering of candidates, i.e. they used a close-list system. In 1998 an open-list system was introduced, although this possibility for voters to order the candidates has little practical impact. In the parliament e.g., only around 10 out of 349 seats are usually allocated differently than otherwise because of the open-list system. Election turnout is high, generally over 80 percent.

Table 1 describes the electoral outcome variables of interest in the empirical analysis. Votes is the municipal election result for a party or coalition and expressed in percentage of all votes. Seats is the representational outcome in the municipal council determined by the election results and the seat assignment rule, and expressed as the percentage of seats received by all parties. As the number of seats is an integer, Seats can only increase discretely. Since Votes is continuous ${ }^{4}$, full proportionality cannot be achieved. Over is the degree of overrepresentation which is calculated as Seats - Votes and is a measure of the deviation from proportionality. Win is a dummy that takes value one if a coalition receives more than 50 percent of the votes and otherwise zero, and Rule is a dummy that takes value one if a coalition receives more than 50 percent of the seats and zero otherwise.

\footnotetext{
${ }^{3}$ First, all votes are divided with 1.4. The party with the highest adjusted number of votes receives the first seat. That party's adjusted number of votes is then divided with a divisor. A new comparison is then made between the parties and the party with the highest adjusted number of votes receives a seat. The procedure is repeated until all seats have been distributed. The divisor series is 3, 5, 7, 9, and so on.

${ }^{4}$ Although this is not true technically Votes is much more continuous than Seats.
} 
Table 1. Description of notation

\begin{tabular}{l|l}
\hline Notation & Description \\
\hline Votes & Percentage of votes received in the election \\
Seats & Percentage of seats received in the municipal council \\
Over & = Seats - Votes, percentage overrepresentation in the municipal council \\
Win & Dummy: 1 if Votes $>50,0$ otherwise \\
Rule & Dummy: 1 if Seats $>50,0$ otherwise \\
\hline M & The moderate party (conservatives) \\
KD & The Christian democratic party \\
FP & The liberal party \\
C & The centre party (agrarian) \\
\hline S & The social democratic party (labor) \\
V & The left party \\
\hline MP & The green party \\
Rest & Other parties, mostly without seats in the parliament \\
\hline Right & Right block consisting of M, KD, FP, and C \\
Left & Left block consisting of S and V \\
\hline
\end{tabular}

Table 1 also lists the seven main parties in Swedish politics, $M, K D, F P, C, S, V$ and $M P$. These are the seven parties that have consistently held seats in the parliament in the sample period. These are also the most important parties at the municipal level. Except $K D$ and $M P$, they have historical roots back to the days of the introduction of universal suffrage. Rest groups together all other parties. Except $M P$, the parties can be ordered along a right-left scale, roughly in descending order in the table, with $M$ generally considered the rightmost and $V$ the leftmost party.

Although Sweden is a genuine multiparty system technically, the politics is rather polarized with two blocks, a right-liberal and a left-socialist block. This has lead e.g. Alesina et al. (1997) and Laver and Shofield (1990) to classify Sweden as a bipartisan system. I let Right denote the right block consisting of $M, K D, F P$, and $C$, and Left denote the left block consisting of $S$ and $V$. This dividing line is commonly accepted. $M P$ is however sometimes also classified as a left-block party as they sometimes, especially at the parliamentary level, are included in left-block governments. The results in this paper are however insensitive to including $M P$ in the left block.

When examining the incumbency effect, I use the variation in discrepancy from proportionality for identification, i.e. the variation in Over. To get a sense of the scope of this variation, Figure 1 plots the frequency distribution for Over where the observations are pooled across parties. Although the discrepancy is small in general, there are rather many observations in absolute terms with substantial over- or underrepresentation. There are e.g. more than 500 observations with over two percent over- or underrepresentation and the extremums span more than ten percent. 


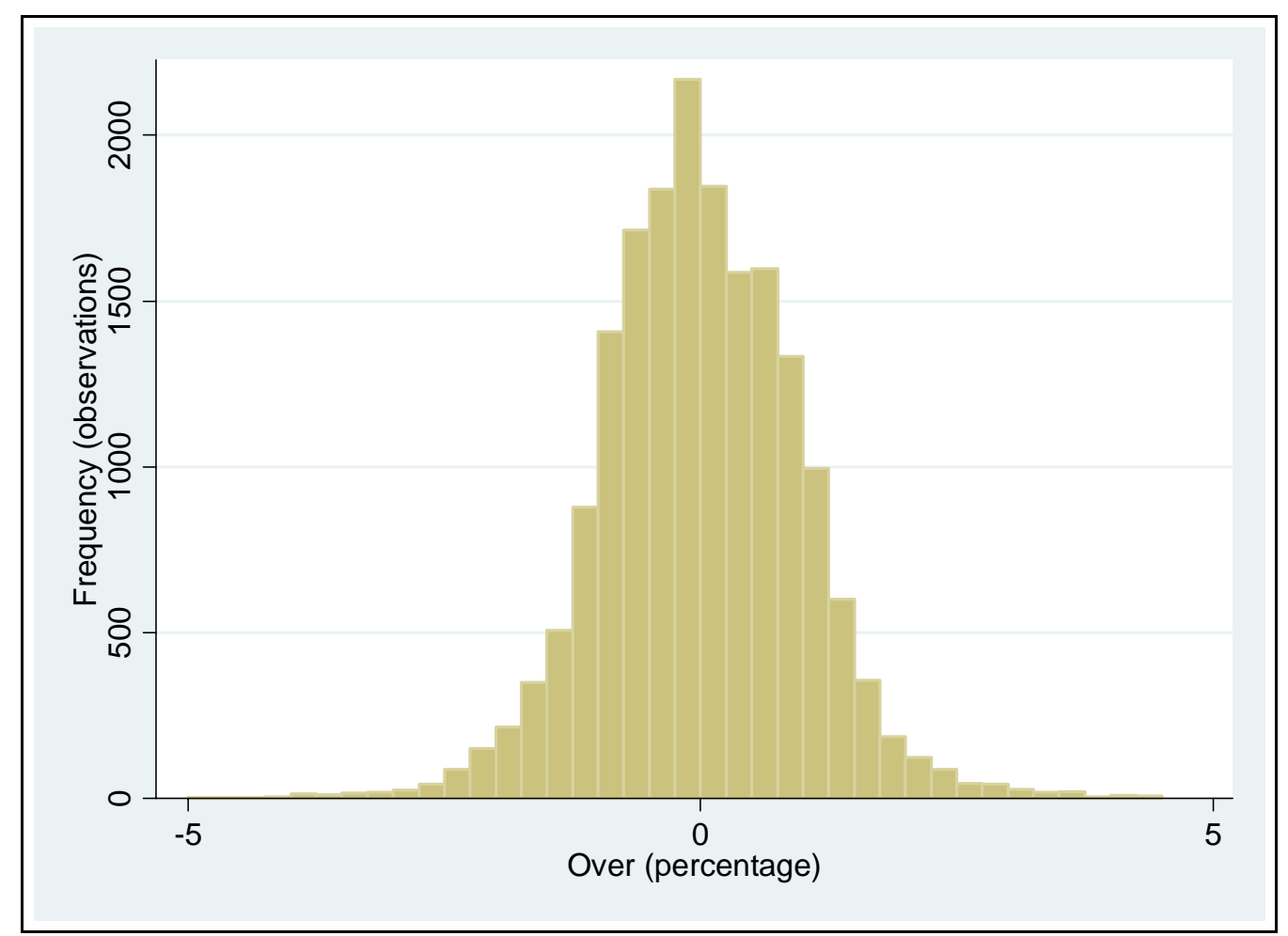

Figure 1. Histogram of overrepresentation

I also analyze the incumbency effect at the party and block level. Table 2 presents descriptive statistics for Votes (without parenthesis) and Over (in parenthesis). We see that the right block consists of four smaller parties whereas the left block consists of one large party and one small party at the municipal level. Standard deviations are high and extremum values show a large span. The average overrepresentation is close to zero and standard deviations around one percent. We can also see that there is a positive correlation between election results and overrepresentation, a pattern produced by the seat distribution method. At the block level, the two blocks are quite equal-sized and show similar distribution. This contrasts the parliamentary level where there is clearer left-wing dominance.

When investigating the effect of ruling, I treat the political system in Sweden as a twoblock system, with the blocks as described above. I define ruling as holding over 50 percent of the seats. In a genuine two-block system, ruling for one block implies that the other block is in opposition and vice versa. However, this is not necessarily the case when there are blockindependent parties. When neither blocks rule, ruling is unclear. Table 3 shows the number of right-wing, left-wing and unclear governments. Although one block usually rules, there are quite many unclear governments and their number increases over time. The results in this paper are however insensitive to several different strategies to deal with these unclear governments. 
Table 2. Descriptive statistics for Votes and Over by party

\begin{tabular}{l|cccc}
\hline Votes and Over & Mean & Std. Dev. & Min & Max \\
\hline $\mathrm{M}$ & 17.476 & 8.563 & 0.254 & 68.070 \\
& $(0.275)$ & $(0.855)$ & $(-2.211)$ & $(4.118)$ \\
$\mathrm{KD}$ & 4.959 & 3.889 & 0 & 44.313 \\
& $(-0.149)$ & $(0.849)$ & $(-4.634)$ & $(2.343)$ \\
$\mathrm{FP}$ & 7.813 & 4.043 & 0.121 & 30.117 \\
& $(0.058)$ & $(0.778)$ & $(-2.442)$ & $(2.956)$ \\
$\mathrm{C}$ & 15.219 & 8.686 & 0.532 & 51.900 \\
& $(0.145)$ & $(0.836)$ & $(-2.886)$ & $(2.778)$ \\
\hline $\mathrm{S}$ & 40.683 & 9.716 & 8.101 & 70.519 \\
& $(0.694)$ & $(1.171)$ & $(-2.677)$ & $(7.017)$ \\
$\mathrm{V}$ & 5.921 & 4.851 & 0 & 58.297 \\
& $(-0.063)$ & $(0.795)$ & $(-3.749)$ & $(3.093)$ \\
\hline MP & 3.373 & 2.380 & 0 & 43.679 \\
& $(-0.223)$ & $(0.807)$ & $(-3.577)$ & $(2.439)$ \\
Rest & 4.555 & 6.077 & 0 & 44.378 \\
& $(-0.737)$ & $(0.992)$ & $(-5.431)$ & $(2.300)$ \\
\hline Right & 45.467 & 11.605 & 10.081 & 87.883 \\
Left & $(0.631)$ & $(1.299)$ & $(-3.102)$ & $(6.509)$ \\
& 46.604 & 11.657 & 8.675 & 82.248 \\
\hline
\end{tabular}

Notes: Votes are shown without parenthesis and Over within parenthesis. There are 2295 observations from eight elections.

Table 3. Number of right-wing, left-wing, and unclear governments

\begin{tabular}{l|cccccccc|c}
\hline Rule & 1982 & 1985 & 1988 & 1991 & 1994 & 1998 & 2002 & 2006 & Sum \\
\hline Right & 115 & 126 & 94 & 143 & 64 & 92 & 99 & 118 & 851 \\
Left & 148 & 127 & 124 & 72 & 145 & 113 & 108 & 70 & 907 \\
Unclear & 21 & 31 & 66 & 71 & 79 & 84 & 83 & 102 & 537 \\
\hline Sum & 284 & 284 & 284 & 286 & 288 & 289 & 290 & 290 & 2295 \\
\hline
\end{tabular}

Although unclear governments may be a problem, the existence of unconventional coalitions where parties exceed the block lines, and minority governments where majority support is gathered on an issue by issue basis, are more problematic. Since I do not have data on the actual coalitions, I cannot distinguish such cases. However, the two-block approximation is common in practice and frequently made in empirical analysis using Swedish election data, e.g. Johansson (2003), Jordahl (2006) and Pettersson-Lidbom (2007). Several of them also find that ruling defined as in such way affects or is affected by other variables. PetterssonLidbom (2007) finds e.g. that left-block ruling causes higher taxes and spending. 


\section{EMPIRICAL STRATEGY}

I define the incumbency effect of representation as the effect of holding seats on the election result in the upcoming election, i.e. the effect of $\operatorname{Seats}_{i, t}$ on $\operatorname{Votes}_{i, t+l}$, where $i$ indexes a party in a local government and $t$ indexes election periods. To examine this effect, I pool data across the seven main parties and Rest, and run the following regression with OLS:

$$
\text { Votes }_{i, t+1}=\beta_{S} \text { Seats }_{i, t}+\boldsymbol{\beta}_{V}^{\prime} \boldsymbol{f}\left(\text { Votes }_{i, t}\right)+\mu_{i}+\lambda_{\text {Party }, t+1}+\varepsilon_{i, t+1} \text {. }
$$

$\boldsymbol{f}\left(\right.$ Votes $\left._{i, t}\right)$ is a polynomial vector in Votes $_{i, t}, \mu_{i}$ a party-specific local government fixed effect, $\lambda_{\text {Party, } t+1}$ a party-specific election year dummy, and $\varepsilon_{i, t+1}$ an idiosyncratic error term. $\beta_{S}$ is an estimate of the incumbency effect and $\boldsymbol{\beta}_{\boldsymbol{V}}$ a parameter vector of the election result persistency.

There is an omitted-variables endogeneity problem when simply running OLS of Votes $_{i, t+1}$ on Seats Sitt as the number of seats is determined by the election result which is persistent between consecutive elections. Therefore we need to control for the effect of Votes $_{i, t}$ on Votes $_{i, t+1}$ and I include a high order polynomial in Votes $_{i, t}$ for this purpose. Identification of the incumbency effect is possible because the incumbency and the election result are not perfectly correlated. In fact, between the thresholds where additional seats are received, there is no correlation between the two variables, as varying the election result slightly does not affect representation. At the thresholds a negligible variation in election results changes incumbency discontinuously. The number of seats received is just the sum of these local discontinuous changes, and clearly has a random component. In fact, we do not even need to know where the thresholds are exactly in each case to use the discontinuities they create.

We can rearrange the two first left-side components in equation (1) as $\beta_{S}$ Seats $_{i, t}+\boldsymbol{\beta}_{\boldsymbol{V}} \boldsymbol{f}\left(\right.$ Votes $\left._{i, t}\right)=\beta_{S}$ Over $_{i, t}+\boldsymbol{\beta}_{\boldsymbol{V}-\boldsymbol{f}} \boldsymbol{f}\left(\right.$ Votes $\left._{i, t}\right)$, where I have subtracted $\beta_{S}$ Votes $_{i, t}$ from the first component and added the same term to the second component. This reformulation shows that the variation used is just the variation in overrepresentation, and it is the randomness in this variable that I try to exploit for causal inference. Over is correlated with Votes for two reasons. Between the thresholds, holding the number of seats constant, there is a perfect negative correlation as Over $=$ Seats - Votes. Across threshold, there is however a positive correlation as the seat assignment method favors larger parties. The election result is therefore an important variable to control for.

Including the election result removes most endogeneity concerns. We may e.g. worry that demographics or charisma of individual politicians affect incumbency which in turn affects the election results in the next election. However, the effect on incumbency has to 
work through the variables determining incumbency. In the present example, demographics or charisma of individual politicians likely affect incumbency through the election result. But since we control for the election result, we have taken care of this channel of causation.

The (over)representation conditional on the election result may however also depend systematically on the threshold structure. For a given seat assignment method, this structure is determined by the distribution of votes across parties and the council size. If the political map in a local government contains few larger parties and a large council the deviations from proportionality is likely smaller. Unfortunately, the influence of these factors on the dependent variable is unlikely to have a simple functional form. Fortunately, the political map is rather stable within local governments. Further, the variation over time has a large common component across local governments, largely influenced by the parties' performances at the parliamentary level. I include party-specific local government fixed effects and party-specific election year dummies to partial out these effects. These dummies are party-specific as the election result cannot be higher for all parties in a local government or at a certain election. Fixed effect and time dummies also reduce error variance and can increase precision.

To address the concern whether all endogeneity has been removed I add a large number of party-specific control variables that may affect the threshold structure or the election result in sensitivity tests. The results stay robust to these tests.

By pooling data across parties, I assume the incumbency effect and the persistency of the election result to be constant across parties. To relax these assumptions, I also estimate party- and block-specific incumbency effects allowing for party- or block-specific election result persistencies, that is, I estimate equation (1) separately for each party and each block. I also test for heterogenous incumbency effects along the incumbency dimension, i.e. for subsamples with the number of seats in different intervals.

I define the ruling effect of representation as the effect of being in the winning coalition on the election result in the upcoming election. Assuming permanent coalitions within blocks, I am interested in the effect of RuleLeft $t_{i, t}$ on VotesLeft $t_{i, t+1}$ for the left block, where $i$ now indexes local governments. I run the following regression equation with OLS:

$$
\text { VotesLeft }_{i, t+1}=\beta_{R} \text { RuleLeft }_{i, t}+\left(\boldsymbol{\beta}_{S}{ }^{\prime}+\boldsymbol{\beta}_{S R}{ }^{\prime} \text { RuleLeft }_{i, t}\right) \boldsymbol{f}\left(\text { SeatsLeft }_{i, t}-50\right)+\varepsilon_{i, t+1} \cdot
$$

$f\left(\right.$ SeatsLeft $\left._{i, t}-50\right)$ is a polynomial vector in SeatsLeft $t_{i, t}$. I use a piecewise polynomial with two independent pieces, one for the non-ruling and one for the ruling side, divided by the threshold where the number of seats reaches 50 percent, i.e. when RuleLeft $t_{i, t}$ switches sign. $\boldsymbol{\beta}_{\boldsymbol{S}}$ and $\boldsymbol{\beta}_{\boldsymbol{S} \boldsymbol{R}}$ are parameter vectors of the polynomial where the former is a general component and 
the latter a component for the ruling side. (These estimates should not be interpreted causally). $\beta_{R}$ is the estimate of the effect of ruling and $\varepsilon_{i, t+1}$ an idiosyncratic error term.

Also here is there an omitted-variables endogeneity problem when simply running OLS of Votes $_{i, t+1}$ on RuleLeft $t_{i, t}$ as ruling depends of the seat distribution, which in turn depends on the election results which are persistent. I include a higher order polynomial in SeatsLeft $t_{i, t}$ to solve the problem. Identification is based on the fact that SeatsLeft $t_{i, t}$ affects VotesLeft $t_{i, t+1}$ continuously $^{5}$, whereas RuleLeft $t_{i, t+1}$ affects VotesLeft $t_{i, t+1}$ discontinuously at SeatsLeft $t_{i, t}=50$ percent. This is the same regression-discontinuity design used by Lee (2007). Further covariates are not needed for consistency as the forcing variable SeatsLeft $t_{i, t}$ fully determines ruling. Ruling is therefore exogenous conditional on the seat distribution. Any variable that affects ruling has to affect it through the seat distribution - a variable that I partial out.

I also examine the effect of ruling on the chance of winning the next election for the left block, i.e. the effect of RuleLeft $t_{i, t}$ on WinLeft $t_{i, t}$. I run the following Probit regression equation:

$$
\operatorname{Pr}\left(\text { WinLeft }_{i, t+1}\right)=\Phi\left[\beta_{R} \text { RuleLeft }_{i, t}+\left(\beta_{S}+\beta_{S R} \text { RuleLeft }_{i, t}\right) \text { SeatsLeft }_{i, t}\right] .
$$

$P(*)$ is the probability of treatment and $\Phi(*)$ the cumulative standard normal distribution. Identification is based on the same regression-discontinuity idea, but here we assume that the influence of the covariates enters differently. I use two piecewise independent terms separated by the ruling threshold here as well. A similar Logit regression gives similar results.

In the regression-discontinuity design, observations close to the threshold help most in identification, as we essentially compare close winners and losers assuming that these two groups become similar when the difference in the forcing variable becomes small. In practice we can either directly compare observations close enough to the thresholds or extrapolate a control function in the forcing variable toward the threshold. The first method is usually less efficient as many observations are discarded, whereas the consistency of the second method relies on fitting the forcing variable properly. In the basic specification, I use the extrapolation method. However, I also run regressions using only observations within ten percent of the votes on each side of the threshold, combined with extrapolation, with the same result.

I present the effect of ruling defined as receiving more than 50 percent of the seats for the left block. However, in a number of sensitivity tests where I define ruling differently or focus on the right block or individual parties, I find that the results are insensitive to this choice of specification. The results are also insensitive to adding further control variables.

\footnotetext{
${ }^{5}$ Again, this is not true technically, but in practice relative to the effect of ruling.
} 


\section{RESULTS}

Table 4 presents the incumbency effect results estimated using equation (1). Along the horizontal dimension, I vary the order of polynomial in Votes $_{i, t}$. I will consistently use up to a fourth order polynomial in this paper. Adding further orders have small additional effects. The specifications in table 4 include party-specific local government fixed effect and election year dummies. I use Huber-White robust standard errors allowing for clustering at the local government level for each party.

Table 4. The incumbency effect on the election result

\begin{tabular}{|c|c|c|c|c|c|}
\hline Dep: Votesi,t+1 & [1] & [2] & $\begin{array}{l}{[3]} \\
\text { ?nd }\end{array}$ & {$[4]$} & [5] \\
\hline Polynomial & & lst & $2^{\text {nd }}$ & 3 rd & $4^{\text {th }}$ \\
\hline Seatsi,t & $\begin{array}{c}0.423^{* * *} \\
(0.020)\end{array}$ & $\begin{array}{c}0.117^{* * * *} \\
(0.029)\end{array}$ & $\begin{array}{c}0.116^{* * * *} \\
(0.030)\end{array}$ & $\begin{array}{c}0.112^{* * * *} \\
(0.029)\end{array}$ & $\begin{array}{c}0.115^{* * * *} \\
(0.029)\end{array}$ \\
\hline Votesi,t & & $\begin{array}{c}0.341^{* * *} \\
(0.039)\end{array}$ & $\begin{array}{c}0.359^{* * * *} \\
(0.041)\end{array}$ & $\begin{array}{c}0.418^{* * * *} \\
(0.047)\end{array}$ & $\begin{array}{c}0.324^{* * * *} \\
(0.056)\end{array}$ \\
\hline 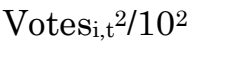 & & & $\begin{array}{l}-0.037 \\
(0.050)\end{array}$ & $\begin{array}{c}-0.341^{*} \\
(0.203)\end{array}$ & $\begin{array}{c}0.550 \\
(0.378)\end{array}$ \\
\hline Votesi, $\mathrm{t}^{3} / 10^{4}$ & & & & $\begin{array}{c}0.362 \\
(0.220)\end{array}$ & $\begin{array}{c}-2.187^{* * *} \\
(0.963)\end{array}$ \\
\hline Votes $_{i, t}{ }^{4} / 10^{6}$ & & & & & $\begin{array}{c}2.170 * * * \\
(0.796)\end{array}$ \\
\hline $\mathrm{FE}^{*}$ Party & Yes & Yes & Yes & Yes & Yes \\
\hline Year*Party & Yes & Yes & Yes & Yes & Yes \\
\hline $\mathrm{R}^{2}$ & 0.48 & 0.49 & 0.49 & 0.49 & 0.49 \\
\hline
\end{tabular}

Notes: 16040 observations are used in each regression. Huber-White robust standard errors allowing for clustering within local governments for each party are in parentheses. * significant at $10 \% ;{ }^{* *}$ significant at $5 \% ; * * *$ significant at $1 \%$.

The estimate of $\operatorname{Seats}_{i, t}$ is an estimate of the incumbency effect. The first column shows a positive effect. However, without controlling for the election result, this estimate is biased. When including a polynomial in Votes $_{i, t}$, removing the positive influence of the election result on the next election result, the point estimate decreases. The estimated effects do not vary much with polynomial order. They are of the order 0.11 percent of the votes for each percent of incumbency and statistically significant at one percent. This is equivalent to an incumbency effect of 11 percent of the seats hold.

Another way to state the size of the effect is that 11 percent of the votes in an upcoming election are determined by the present seat distribution. A party that holds all the seats would therefore enjoy and incumbency advantage of 11 percent compared to the other parties. This advantage is close to the incumbency advantage found in majoritarian systems. It is large and economically significant. However, in practice, parties seldom hold all seats in councils in 
multi-member districts in proportional systems, which they always do in single-member districts in majoritarian systems. Although the advantage is of the same size in percentage of incumbency, the relative incumbency effect of parties compared to other parties is much smaller because incumbency is more evenly share across parties in proportional systems. A party that holds a small majority of the seats enjoys a 5.5 percent advantage compared to a party without seats. The variation in overrepresentation spans 10 percent of the seats. Such a difference in incumbency only induces a relative incumbency effect of 1.1 percent of the votes.

The causal interpretation requires that I have partialled out all effects of the election results and the threshold structure. If this is the case, adding further control variables should not affect the estimates. I have conducted sensitivity tests where I add a large number of controls. The first group of controls consists of council size and the number of eligible voters which may affect the threshold structure. The second group consists of population, population changes, population density, per capita tax base, percentage of population under 18, and percentage of population over 65. These demographic variables may affect the election results. The third group is a set of dummies describing whether there was a left block, right block, or unclear government before the election. This is to control for eventual effects of ruling (the estimated effects are not causal in this setting).

We should not include control variables that are determined after the main variable. ${ }^{6}$ I therefore include controls from the same election as $\operatorname{Seats}_{i, t}$, i.e. from period $t$ which is one period prior to the dependent variable from period $t+1$. Many of these controls are significant. However, including them does not change point estimates or standard errors of the incumbency effect much. ${ }^{7}$ Another sensitivity test that I have performed is to leave out local governments involved in local government redistricting (splittings). The results stay the same.

Table 5 presents the party-wise incumbency effect results. Each estimate is an estimate of the incumbency effect for one party from one separate regression. I leave out the election result polynomial estimates. I vary the polynomial order along the horizontal dimension and party along the vertical dimension. All specifications include local government fixed effects and election year dummies. Standard errors are clustered at the local government level.

\footnotetext{
${ }^{6}$ Using the terminology from the treatment literature, we should only include predetermined controls, i.e. variables determined prior to treatment. Including post-treatment variables removes the effect of treatment that works through these variables and may bias the results.

${ }^{7}$ The sensible variables to include in a kitchen sink approach are control variables from the same election as the dependent variables, i.e. from period $t+1$, for the first two groups of control variables as we expect an immediate effect of these variables on election results. In the present case, using these controls instead, produces the same result, although such an approach may bias the results according to the previous footnote.
} 
Table 5. The incumbency effect on the election result by party

\begin{tabular}{l|ccccc}
\hline Dep: Votesi,t+1 & {$[1]$} & {$[2]$} & {$[3]$} & {$[4]$} & {$[5]$} \\
Polynomials & None & $1^{\text {st }}$ & $2^{\text {nd }}$ & $3 \mathrm{rd}$ & $4^{\text {th }}$ \\
\hline $\mathrm{M}$ & $0.360^{* * *}$ & $0.139^{*}$ & $0.149^{* *}$ & $0.142^{* *}$ & $0.140^{* *}$ \\
& $(0.045)$ & $(0.072)$ & $(0.072)$ & $(0.071)$ & $(0.071)$ \\
$\mathrm{KD}$ & $0.478^{* * *}$ & $0.075^{*}$ & $0.096^{* *}$ & $0.074^{*}$ & $0.080^{*}$ \\
& $(0.080)$ & $(0.042)$ & $(0.046)$ & $(0.043)$ & $(0.044)$ \\
$\mathrm{FP}$ & $0.270^{* * *}$ & $0.108^{*}$ & 0.103 & 0.083 & 0.080 \\
& $(0.028)$ & $(0.063)$ & $(0.063)$ & $(0.064)$ & $(0.064)$ \\
$\mathrm{C}$ & $0.486^{* * *}$ & $0.134^{*}$ & 0.129 & $0.141^{*}$ & $0.149^{*}$ \\
& $(0.040)$ & $(0.081)$ & $(0.084)$ & $(0.084)$ & $(0.084)$ \\
\hline $\mathrm{S}$ & $0.362^{* * *}$ & 0.058 & 0.055 & 0.053 & 0.053 \\
& $(0.030)$ & $(0.076)$ & $(0.076)$ & $(0.076)$ & $(0.076)$ \\
$\mathrm{V}$ & $0.528^{* * *}$ & $0.141^{*}$ & $0.166^{* *}$ & $0.124^{*}$ & $0.128^{*}$ \\
& $(0.100)$ & $(0.077)$ & $(0.073)$ & $(0.073)$ & $(0.075)$ \\
\hline MP & $0.231^{* * *}$ & $0.153^{* *}$ & $0.088^{* *}$ & $0.088^{* *}$ & $0.091^{* *}$ \\
& $(0.019)$ & $(0.061)$ & $(0.040)$ & $(0.042)$ & $(0.043)$ \\
Rest & $0.482^{* * *}$ & $0.237^{*}$ & $0.234^{*}$ & $0.240^{* *}$ & 0.187 \\
& $(0.040)$ & $(0.139)$ & $(0.140)$ & $(0.142)$ & $(0.138)$ \\
\hline Right & $0.438^{* * *}$ & $0.147^{* *}$ & $0.145^{* *}$ & $0.145^{* *}$ & $0.145^{* *}$ \\
& $(0.036)$ & $(0.061)$ & $(0.061)$ & $(0.061)$ & $(0.061)$ \\
Left & $0.376^{* * *}$ & 0.037 & 0.035 & 0.021 & 0.021 \\
& $(0.036)$ & $(0.076)$ & $(0.075)$ & $(0.074)$ & $(0.074)$ \\
\hline FE & Yes & Yes & Yes & Yes & Yes \\
Year & Yes & Yes & Yes & Yes & Yes \\
\hline
\end{tabular}

Notes: Each estimate is an estimate of Seatsi,t for one party from one separate regression. Polynomials refer to polynomials in Votesi,t. 2005 observations are used in each regression. HuberWhite robust standard errors allowing for clustering within local governments are in parentheses. * significant at $10 \% ; * *$ significant at $5 \% ; * * *$ significant at $1 \%$.

The estimates vary somewhat with polynomial order, but are quite stable between the higher order specifications. The incumbency effect varies from 0.05 to 0.19 percent of the votes for each percent of incumbency with the lowest value for $S$ and the highest value for Rest. Statistical confidence levels vary, but the estimates are significant for a majority of the parties. For the right-wing parties, the incumbency effect is larger for the two larger parties and smaller for the two smaller parties. For the left-wing parties the incumbency effect is largest for the smaller party and smaller for the larger party. The differences between many pairs of parties are statistically significant, both for parties within and between blocks. The incumbency effect at the block level is close to the effects for the larger parties in the block, that is, higher than average for the right block and much lower than average for the left block. Also this difference is statistically significant.

I have also tested whether the effect is heterogeneous as incumbency varies. First, I have analyzed the effect for the first seat received by only using the observations where the number of seats equals zero or one. This effect is close to the average effect. Second, I have 
analyzed the effect for six nonoverlapping but collectively exhaustive subsamples within different intervals of incumbency. The effects are somewhat larger than the average effect for subsamples with less than 30 percent of the seats and about half the effect otherwise.

Table 6 presents the effect of ruling results for the left block estimated using equation (2) and (3). Column [1] to [5] shows the effect on the votes received and column [6] the effect on the chance of winning the next election. Each estimate is an estimate from one separate regression. I vary the election result polynomial order along the horizontal dimension, but leave out these estimates. For the Probit estimate in column [6] I use a linear polynomial and present the marginal effect estimates in percentages.

The Full row shows the basic result for the full sample. The last three rows show sensitivity tests. The $10 \%$ row limits the sample to ten percent around the threshold to reduce potential bias caused by potentially misfitted polynomials. The FE+Year row adds local government fixed effects and election year dummies to the basic full sample analysis. The $F E+$ Year + Con row further add a large number of controls variables. These are the same controls used in the sensitivity tests of the incumbency effect (except for controls for ruling as ruling is included as the main independent variable). As discussed, the proper controls to add are controls from the same period as LeftRule $_{i, t}$, i.e. from period $t$. I also add Votes $_{i, t}$ as a control here (it was included as a main covariate in the incumbency effect analysis). If ruling is exogenous conditional on the seat distribution, adding controls should not affect the estimated effect. Standard errors are again clustered at the local government level.

Table 6. The effect of ruling on the election result for the left block

\begin{tabular}{l|ccccc|c}
\hline Dep: Votesi,t+1 & {$[1]$} & {$[2]$} & {$[3]$} & {$[4]$} & {$[5]$} & $(6)$ \\
Polynomials & None & $1^{\text {st }}$ & 2 nd & $3^{\text {rd }}$ & $4^{\text {th }}$ & Probit \\
\hline Full & $16.630^{* * *}$ & -0.537 & 0.049 & -0.228 & 0.192 & -2.593 \\
& $(0.811)$ & $(0.485)$ & $(0.627)$ & $(0.749)$ & $(0.884)$ & $(4.142)$ \\
$10 \%$ & $8.078^{* * *}$ & -0.172 & 0.020 & -0.111 & -0.040 & -1.458 \\
& $(0.509)$ & $(0.611)$ & $(0.887)$ & $(1.495)$ & $(2.792)$ & $(5.406)$ \\
\hline FE+Year & $1.250^{* * *}$ & $-1.110^{* * *}$ & -0.136 & -0.716 & -0.494 & \\
& $(0.386)$ & $(0.341)$ & $(0.416)$ & $(0.468)$ & $(0.561)$ & \\
FE+Year+Con & $-1.133^{* * *}$ & $-1.285^{* * *}$ & -0.303 & -0.408 & -0.179 & \\
& $(0.378)$ & $(0.378)$ & $(0.446)$ & $(0.534)$ & $(0.642)$ & \\
\hline
\end{tabular}

Notes: VotesLeft $t_{i, t+1}$ is the dependent variable in [1] to [5], and $\operatorname{Pr}\left(\right.$ WinLeft $\left._{i, t+1}\right)$ is the dependent variable in (6). Each estimate is an estimate of RuleLeft $t_{i, t}$ from one separate regression. Polynomials refer to polynomials in Votesi,t. Probit includes a linear term in Votest. The polynomials are independently estimated for the RuleLeft $t_{i, t}=0$ and the RuleLeft $t_{i, t}=1$ sides in all regressions. 2005 observations are used in each regression. Huber-White robust standard errors allowing for clustering within local governments are in parentheses. * significant at $10 \%$; ** significant at $5 \% ; * * *$ significant at $1 \%$. 
First, we focus on Column [1]. When using the full sample, the estimated effect is large and positive, indicating a positive raw correlation. When confined to ten percent around the threshold the estimated effect decreases. As fixed effects and year dummies are added, the estimated effect decreases further, but is still statistically significantly positive. When the control variables are added, the estimated effect turns statistically significantly negative. ${ }^{8}$ The last two estimated effects are kitchen sink approaches with different set of controls. They show that the sign of the result depend on which set of controls we include.

The last row result also shows that I can replicate the cost-of-ruling result found in other papers, although using my most extensive set of control variables produces a 1.1 percent cost of ruling than the 2 percent that is usually found. Experimenting with yet other combination of controls, I can however produce both larger and smaller benefits as well as costs of ruling. ${ }^{9}$ But serious doubts can be raised against interpreting the kitchen sink estimates as causal effects.

In the Columns [2] to [5], I control for the forcing variable using different polynomials. As discussed, including this variable is necessary for consistency. In fact, this is the only variable we need to partial out for consistency. We see that the estimated effect disappears as polynomial orders are added. For the higher order specifications, the estimated effects are statistically insignificant. The results stay robust when using the ten percent sample as well as when adding different sets of control variables, as it should be if we have removed all endogeneity. The size of the estimates is also very small; for the fourth order specification, the in absolute terms largest estimated effect is a cost of ruling of 0.54 percent of the votes, which is an economically insignificant effect.

Standard errors increases when confining to the ten percent sample as expected. They decreases as fixed effects and year dummies are added, and increases as further controls are added. The FE+Year specification with the highest precision has standard errors small enough to rule out a one percent effect of ruling. My results therefore indicate a quite certain absence of an effect of ruling.

The Probit estimates show that ruling does not affect the chance of winning the next election much. The estimated effect is -2.6 percent in the full sample and reduces to -1.35

\footnotetext{
${ }^{8}$ Fallaciously including control variables from the same period as the dependent variable, i.e. from $t+1$ (See footnote 6 and 7) for all variables except Votes $_{t}$ gives similar results.

${ }^{9}$ The two set of controls I have chosen to focus on here are chosen to serve as sensitivity test in the polynomial specifications rather than to exactly replicate the results from previous studies. Fixed effects and year dummies are standard covariates in panel regressions and the other controls are simply the most extensive set that I have at my disposal.
} 
percent in the ten percent sample. Both estimated effects are statistically insignificant and small in practice as well. Corresponding estimates using Logit give similar results.

I have conducted a number of sensitivity tests not presented here. First, I have included $M P$ as a left block party, with the same result. Second, I have redefined ruling as holding more than 50 percent of the sum of the two blocks' seats, again with the same result. Third, I have excluded observations with unclear governments, and find that the estimated effect of ruling stays unchanged. Fourth, I have eliminated one election period at a time, starting with the last election, to deal with unclear governments with large numbers of unclear governments (as can be seen from table 3), with similar result after each elimination. Fifth, I have included a dummy to allow unclear ruling to have an independent effect on the electoral outcome. The effect of ruling is still unaffected, and the effect of unclear ruling is close to zero as well.

Sixth, I have run the corresponding regressions for the right block, and find the same absence of effects of ruling. Seventh, I have examined the effect of ruling in a coalition with other parties on the election results for each of the parties individually, without finding any party-specific effects. Finally, I remove local governments involved in redistricting (splittings) from the sample, and neither this changes the results.

To illustrate the estimated results graphically, Figure 2 plots the local averages of VotesLeft $_{i, t+1}$ against SeatsLeft $t_{i, t}$. I divide the x-axis into 250 non-overlapping bins each spanning 0.4 percent of the votes, and let a dot represent the average of the observations in a bin along the y-dimension and the midpoint of the bin along the x-dimension. I plot the fitted line for the full sample basic regression with a piecewise fourth order polynomial allowing for a jump as ruling switches. A vertical dashed line indicates when the switch takes place. We see from the local averages that the relationship is smooth. Nothing particular happens as ruling switches compared to elsewhere. The jump allowed for in the specification cannot be distinguished visually. There are clearly no effects of ruling.

Figure 3 plots the local averages of $\operatorname{Pr}\left(\right.$ WinLeft $\left._{i, t+1}\right)$ against SeatsLeft $t_{i, t}$. The dots are similarly constructed as above, and the fitted line using Probit is plotted. Again, nothing particular happens as ruling switches compared to elsewhere and the jump in the fitted line is hardly visible. Unsurprisingly, ruling does not affect the chance of winning the upcoming election either. 


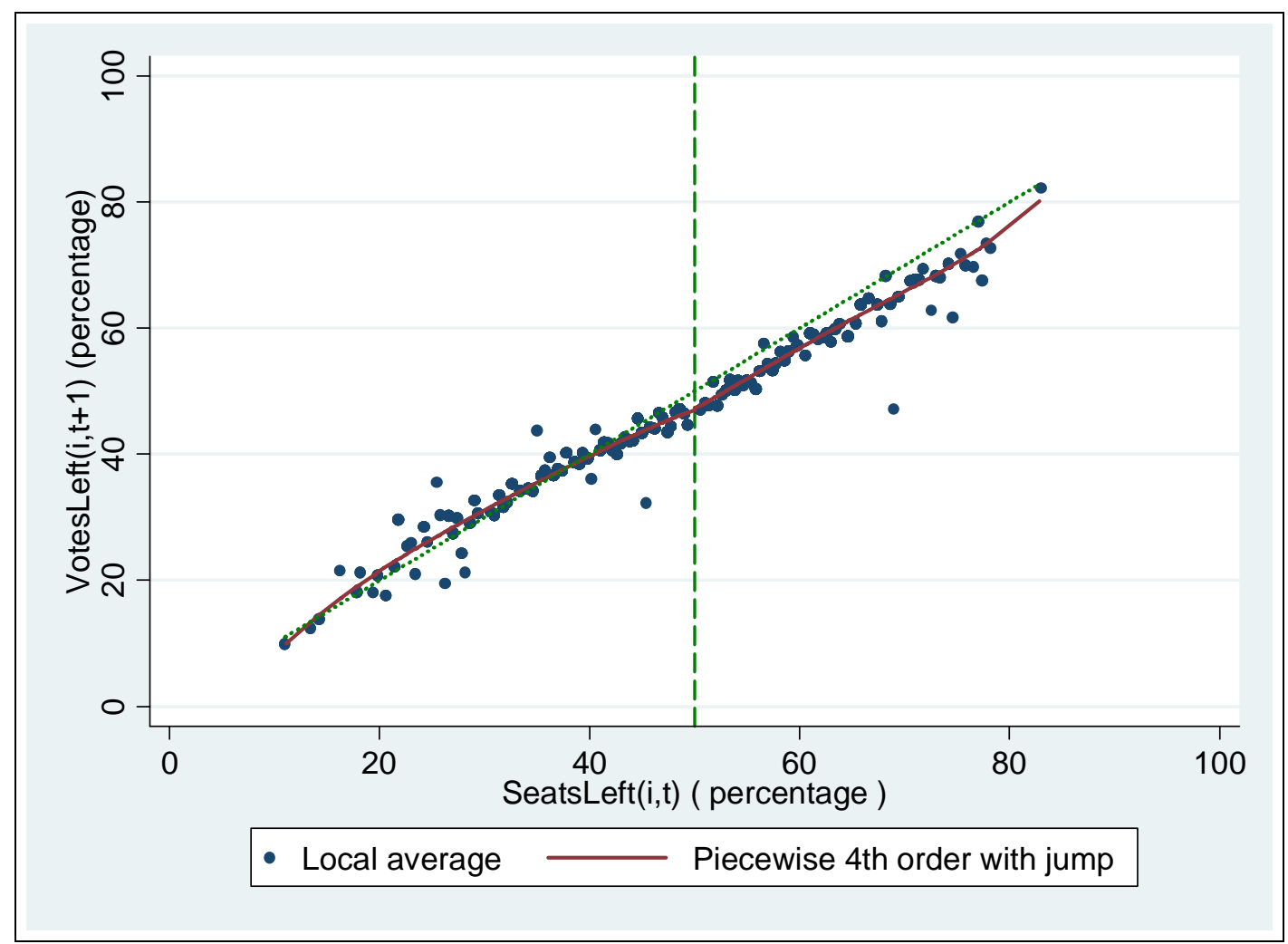

Figure 2. The effect of ruling on the votes received

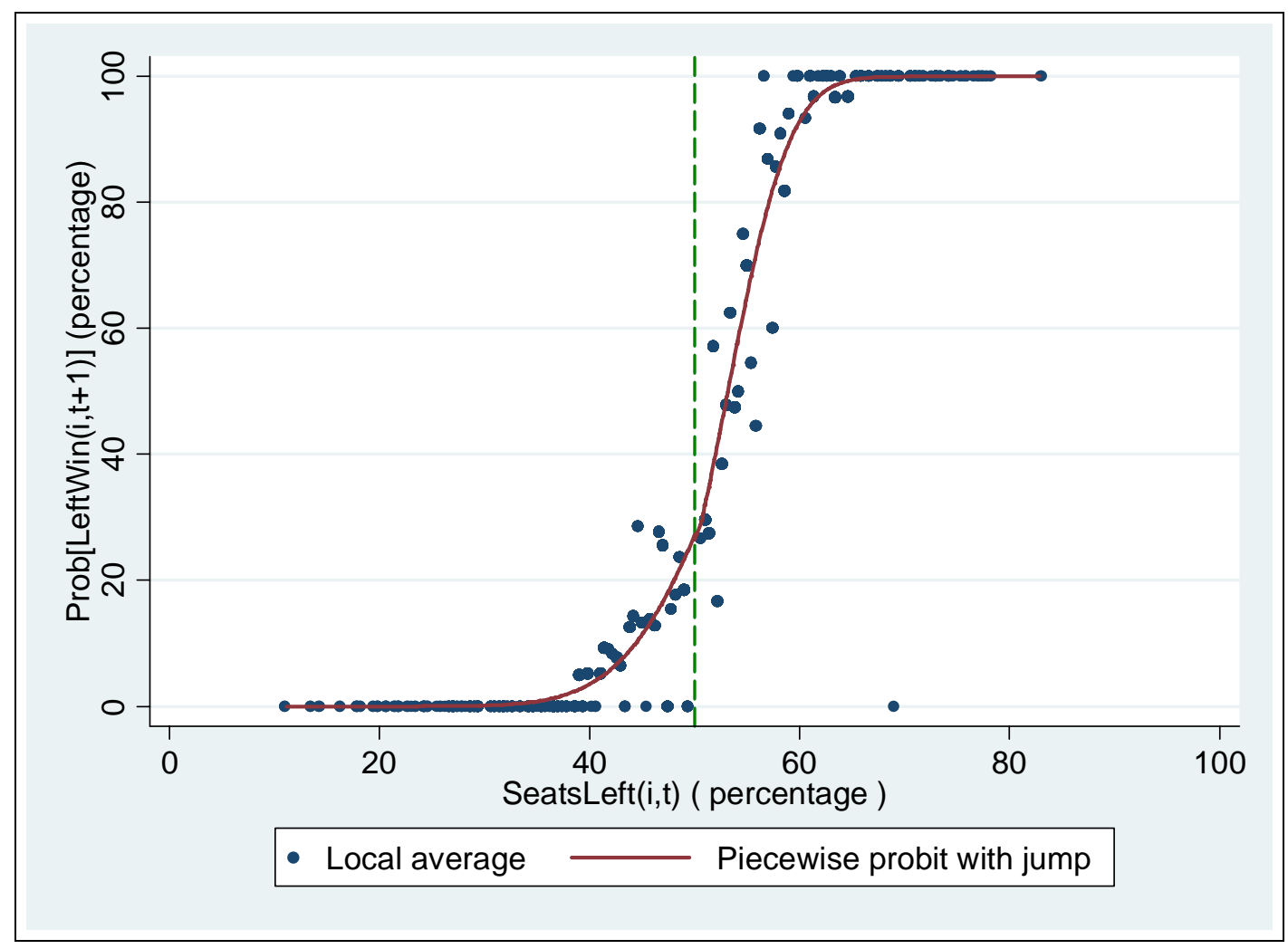

Figure 3. The effect of ruling on win probabilities 
Figure 2 and 3 also show that holding a small majority of the seats generally leads to less than 50 percent of the votes and less than half the chance to win the next election. A larger majority is required, before the ruling coalition becomes favorites. I also add a diagonal line with unit slope in Figure 2. We see that most local averages above 40 percent of the seats lie below this line. Performing well in an election is therefore associated with performing less well in the next election. There is a smaller opposite behavior for the local averages below 40 percent. This is a reversion-toward-40-percent pattern, which is consistent with the backswinging explanation of the cost of ruling. However, this is a non-causal effect of holding seats on the election result in the next election, and not a causal effect of ruling.

\section{CONCLUSIONS}

I have estimated two effects of political representation on the electoral outcome at the local government level in Sweden which has a multiparty proportional election system. I find an advantage of 0.11 percent of the votes for each percent of incumbency. This means that 11 percent of the votes in an election are determined by incumbency. The advantage varies significantly between parties. However, I find no effects of ruling.

The extra resources that parties with larger incumbency receive therefore give these parties an electoral advantage in proportional election systems as well. This advantage is similar in size as the advantage in majoritarian systems. This result may be unexpected as the focus lies on parties rather than individuals in proportional systems. It seems reasonable to expect that the incentives for incumbents to promote their party's popularity in proportional systems are fewer than the incentives to promote their own popularity in majoritarian systems, as there may be a free-riding problem among incumbents from the same party. The results here do not support such a hypothesis, neither that image building is less important for parties than for individuals. Why the advantage differs between parties is however an interesting issue to investigate for future research.

The absence of any effects of ruling rejects the asymmetric voter evaluation hypothesis as well as the median-gap model. Voters do not punish ruling coalitions more for bad events than reward them for good event, nor does the median-voter vote alternatingly. However, the absence of a cost of ruling is compatible with the back-swinging hypothesis. Performing better than usual in an election may be associated with performing less well in the following election as performance returns to its natural level. 


\section{REFERENCES}

Alesina, A., N. Roubini, and G. Cohen (1997), Political Cycles and the Macro Economy, Cambridge: MIT Press.

Andersson, S. P. and G. Glomm (1992), “Incumbency Effects in Political Campaigns”, Public Choice 74, 207-219.

Bernhardt, M. D. and D. E. Ingerman (1985), "Candidate Reputations and the Incumbency Effect”, Journal of Public Economics 27, 47-67.

Collie, M. P. (1981), "Incumbency, Electoral Safety, and Turnover in the House of Representatives 1952-1976”, American Political Science Review, 17-34.

Cox, G. and J. Katz (1996), "Why Did the Incumbency Advantage Grow”, American Journal of Political Science 40, 478-497.

Erikson R. S. (1971), “The Advantage of Incumbency in Congressional Elections”, Polity 3, 395-405.

Gelman, A. and G. King (1990), “Estimating Incumbency Advantage without Bias”, American Journal of Political Science 34, 1142-64.

Johansson, E. (2003), “Intergovernmental Grants as a Tactical Instrument: Empirical Evidence from Swedish Municipalities”, Journal of Public Economics 87, 883-915.

Jordahl, H. (2006), “An Economic Analysis of Voting in Sweden”, Public Choice 127, 251273.

Laver, M. and N. Schofield (1990), Multiparty Government: The Politics of Coalition in Europe, Oxford: Oxford University Press.

Lee, D. (2007), "Randomized Experiments from Non-random Selection in U.S. House Elections”, Journal of Econometrics, forthcoming.

Mueller, J.E. (1971), “Presidential Popularity from Truman to Johnson”, American Political Science Review 64, 18-34.

Nannestad, P. and M. Paldam (1994), "The VP-function: A Survey of the Literature on Vote and Popularity Functions after 25 Years”, Public Choice 79, 213-245.

Paldam, M. (1986), “The Distribution of Election Results and the Two Explanations of the Cost of Ruling”, European Journal of Political Economy 2, 5-24.

Paldam, M. and P. Skott (1995), “A Rational Voter Explanation of the Cost of Ruling”, Public Choice 83, 159-172.

Pettersson-Lidbom, P. (2007), "Do Parties Matter for Economic Outcomes? A RegressionDiscontinuity Approach”, Journal of European Economic Association, forthcoming. 
WORKING PAPERS*

Editor: Nils Gottfries

2006:29 Jonas Björnerstedt and Andreas Westermark, Delay in Bargaining with Externalities. 27pp.

2006:30 Pär Österholm, Incorporating Judgement in Fan Charts. 36pp.

2006:31 Mikael Carlsson and Andreas Westermark, Monetary Policy and Staggered Wage Bargaining when Prices are Sticky. 26pp.

2007:1 Mikael Elinder, Local Economies and General Elections. 26pp.

2007:2 Ouarda Merrouche, The Long Term Impact of French Settlement on Education in Algeria. 19pp.

2007:3 Ouarda Merrouche, The Long Term Effect of Education Spending Decentralization on Human Capital in Spain. 15pp.

2007:4 Erik Post, Macroeconomic imbalances and exchange rate regime shifts. 38pp.

2007:5 Christian Andersson, Teacher density and student achievement in Swedish compulsory schools. 31pp.

2007:6 Thomas Aronsson, Sören Blomquist and Luca Micheletto, Where Should the Elderly Live and Who Should Pay for their Care? A Study in Demographics and Geographical Economics. 22pp.

2007:7 Sören Blomquist and Vidar Christiansen, Public Provision of Private Goods and Nondistortionary Marginal Tax Rates. 17pp.

2007:8 Marcus Eliason and Henry Ohlsson, Living to Save Taxes. 13pp.

2007:9 Åsa Ahlin and Eva Mörk, Effects of decentralization on school resources: Sweden 1989-2002. 31pp.

2007:10 Henry Ohlsson, The equal division puzzle - empirical evidence on intergenerational transfers in Sweden. 20pp.

2007:11 Daniel Hallberg and Mårten Lagergren, Moving in and out of public geriatric care in Sweden. 26pp.

2007:12 Per Engström, Wage Formation and Redistribution. 22pp.

2007:13 Henry Ohlsson, Tax avoidance - a natural experiment. 21pp.

2007:14 David Kjellberg and Erik Post, A Critical Look at Measures of Macroeconomic Uncertainty. 27pp.

\footnotetext{
* A list of papers in this series from earlier years will be sent on request by the department.
} 
2007:15 Mikael Carlsson and Andreas Westermark, Optimal Monetary Policy under Downward Nominal Wage Rigidity. 52pp.

2007:16 Robin Douhan and Anders Nordberg, Is the elephant stepping on its trunk? The problem of India's unbalanced growth. 33pp.

2007:17 Annika Alexius and Bertil Holmlund, Monetary Policy and Swedish Unemployment Fluctuations. 27pp.

2007:18 Meredith Beechey and Pär Österholm, The Rise and Fall of U.S. Inflation Persistence. 23pp.

2007:19 Henry Ohlsson and Donald Storrie, Long term effects of public policy for displaced workers in Sweden - shipyard workers in the West and miners in the North. 26pp.

2007:20 Niklas Bengtsson, How responsive is body weight to transitory income changes? Evidence from rural Tanzania. 38pp.

2007:21 Karin Edmark, Strategic Competition in Swedish Local Spending on Childcare, Schooling and Care for the Elderly. 38pp.

2007:22 Fredrik Johansson, How to Adjust for Nonignorable Nonresponse: Calibration, Heckit or FIML? 25pp.

2007:23 Henry Ohlsson, The legacy of the Swedish gift and inheritance tax, 18842004. 25pp.

2007:24 Ranjula Bali Swain and Fan Yang Wallentin, DOES MICROFINANCE EMPOWER WOMEN? Evidence from Self Help Groups in India. 26pp.

2007:25 Bertil Holmlund and Martin Söderström, Estimating Income Responses to Tax Changes: A Dynamic Panel Data Approach. 34pp.

2007:26 N. Anders Klevmarken, Simulating the future of the Swedish baby-boom generations. 60pp.

2007:27 Olof Åslund and Oskar Nordström Skans, How to Measure Segregation Conditional on the Distribution of Covariates. 17pp.

2007:28 Che-Yuan Liang, Is There an Incumbency Advantage or a Cost of Ruling in Proportional Election Systems? 20pp.

See also working papers published by the Office of Labour Market Policy Evaluation http://www.ifau.se/ 